\title{
A Case Report and Review of B-Lineage Acute Lymphoblastic Leukemias with Cannibalistic Lymphoblasts: A Unique Morphologic and Molecular Genetic Entity?
}

\begin{abstract}
Cannibalism is a type of "cell-in-cell" phenomenon commonly described in myeloid lineage malignancies. Although lymphocytes and their precursors are inherently non-phagocytic, there are sporadic case reports describing cannibalism by leukemic lymphoblasts. In the current manuscript, we report the case of a pediatric B-lineage acute lymphoblastic leukemia (B-ALL) patient showing cannibalistic lymphoblasts and have reviewed the clinical and laboratory characteristics of similar cases documented in literature. Our manuscript highlights that all reported B-ALL patients showing cannibalistic lymphoblasts had intra-cytoplasmic vacuolations, and all such treatment-naïve pediatric patients were ETV6-RUNX1 fusion positive and had aberrant expression of myeloid lineage antigens.
\end{abstract}

Keywords: Cannibalism, ETV6-RUNX1, pediatric, precursor B-lineage acute lymphoblastic leukemia

\section{Introduction}

Cannibalism by leukemic blasts is well described in acute myeloid leukemias (AML). Although lymphocytes and their precursors are inherently nonphagocytic, nine cases of leukemic lymphoblasts exhibiting phagocytosis have been documented in literature. ${ }^{[1-6]}$ Through this manuscript, we report our pediatric B-lineage acute lymphoblastic leukemia (B-ALL) patient who had cannibalistic blasts at diagnosis and review the clinical and laboratory characteristics of similar cases reported in literature. Interestingly, all lymphoblastic leukemia patients with phagocytic lymphoblasts reported till date had unique morphologic features and all pediatric B-ALL patients $(100 \%)$ of this genre were positive for ETV6-RUNX1 fusion transcript.

\section{Case Scenario}

A 14-year-old Indian male presented with extreme fatigue and myalgia for 1 month. He was afebrile and had marked pallor and hepatomegaly. Hemogram revealed hemoglobin of $49 \mathrm{~g} / \mathrm{L}$, platelets of $127 \times 10^{9} / \mathrm{L}$, and leukocytes of $15.8 \times 10^{9} / \mathrm{L}$.

\footnotetext{
This is an open access journal, and articles are distributed under the terms of the Creative Commons Attribution-NonCommercial-ShareAlike 4.0 License, which allows others to remix, tweak, and build upon the work non-commercially, as long as appropriate credit is given and the new creations are licensed under the identical terms.
}

For reprints contact: WKHLRPMedknow_reprints@wolterskluwer.com
Myeloperoxidase (MPO)-negative blasts comprised $75 \%$ of circulating leukocytes and $96 \%$ of bone marrow nucleated cells. These blasts were 2-4 times the size of a mature lymphocyte, had opened up chromatin and scanty basophilic cytoplasm. Multiple cytoplasmic vacuolations were observed in $88 \%$ of the blasts, and $12 \%$ of blasts showed erythrophagocytosis or thrombophagocytosis or cannibalism [Figure 1]. Flow cytometric immunophenotyping (FCI) was consistent with B-ALL with aberrant myeloid lineage marker expression (CD19 ${ }^{\text {moderate, }}$ CD10 $0^{\text {bright }}, \mathrm{HLA}-\mathrm{DR} \mathrm{R}^{\text {moderate }}, \mathrm{CD} 34^{\text {dim to moderate }}$, CD13 ${ }^{\text {moderate }}, \mathrm{CD} 33^{\text {moderate }}, \mathrm{CD} 36^{\text {negative to }}$ dim, cytoplasmic CD79a $\mathrm{a}^{\text {moderate, }}$ cytoplasmic CD22 $2^{\text {moderate, }} \quad$ cytoplasmic MPO $^{\text {negative }}$, and cytoplasmic CD3 $\left.{ }^{\text {negative }}\right)$. Qualitative reverse-transcriptase-polymerase chain reaction revealed ETV6-RUNX1 fusion transcript positivity. There was no leukemic central nervous system infiltration at diagnosis.

After the confirmation of diagnosis, the patient's family was counseled about the disease and treatment options. Due to financial constraints, the family wished to continue therapy at the local place. Hence, he was started on 6-week induction with low-dose chemotherapy protocol comprising

How to cite this article: Bommannan BK, Sachdeva MU, Naseem S, Khadwal A, Varma N. A case report and review of $B$-lineage acute lymphoblastic leukemias with cannibalistic lymphoblasts: $A$ unique morphologic and molecular genetic entity? Indian J Med Paediatr Oncol 2020;41:917-9.

\section{B K Karthik \\ Bommannan ${ }^{1}$, Man Updesh Singh Sachdeva ${ }^{1}$, Shano Naseem ${ }^{1}$, Alka Khadwal'2, Neelam Varma ${ }^{1}$}

${ }^{l}$ Department of Hematology, Postgraduate Institute of Medical Education and Research, Chandigarh, India, ${ }^{2}$ Department of Internal Medicine, Postgraduate Institute of Medical Education and Research, Chandigarh, India

Submitted: 04-Jun-2020 Revised: 04-Aug-2020 Accepted: 05-Sep-2020 Published: $31-$ Dec-2020

Address for correspondence: Prof. Man Updesh Singh Sachdeva,

Department of Hematology, Postgraduate Institute of Medical

Education and Research, Chandigarh - 160 012, India. E-mail:drmanupdeshpgi@ yahoo.co.in

Access this article online Website: www.ijmpo.org DOI: 10.4103/ijmpo.ijmpo_280_20 Quick Response Code:

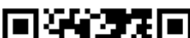

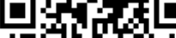

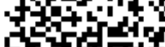

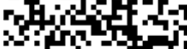

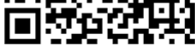




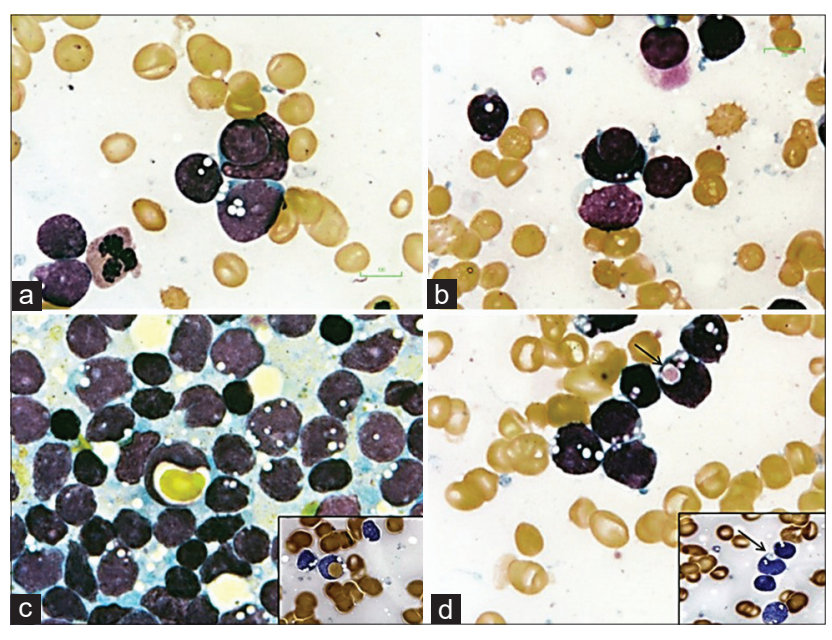

Figure 1: Note the presence of prominent vacuolations in the blasts. ( $a$ and b) Blasts showing cannibalism; (c) blast with erythrophagocytosis. Inset shows myeloperoxidase-positive erythrocyte engulfed by a blast; (d) thrombophagocytosis by blast. Inset shows myeloperoxidase-negative platelet engulfed by a blast. All slides are May-Grünwald-Giemsa stained, and the insets are cytochemical-myeloperoxidase stained $(\times 100)$

weekly vincristine $1.5 \mathrm{mg} / \mathrm{m}^{2}$ and daily prednisolone 60 $\mathrm{mg} / \mathrm{m}^{2}$ for 4 weeks followed by taper. The patient never followed up after he was discharged after receiving week 1 induction. As per telephonic information, the patient was shifted to indigenous treatment and succumbed to his illness after 7 months of diagnosis.

\section{Discussion}

Cellular cannibalism is a type of "cell-into-cell" phenomenon, wherein a viable cell is irreversibly engulfed by a nonprofessional phagocyte. ${ }^{[7]}$ A cannibalistic cell can engulf a cell of its own lineage (homotypic cannibalism) or of different lineage (xeno-cannibalism). ${ }^{[8]}$ Cannibalism is different from phagocytosis, wherein the latter involves a professional phagocytic cell (histiocyte/macrophage) engulfing a nonviable cell. ${ }^{[7,8]}$ Though phagocytosis can be seen in both benign and malignant pathologies, cannibalism is pathognomonic of advanced malignancies. ${ }^{[8]}$

Among acute leukemias, xeno-cannibalism in the form of erythrophagocytosis by neoplastic blasts has been commonly documented in cases of AML with monocyte lineage differentiation, AML with maturation, AML without maturation, acute megakaryoblastic leukemia, mixed phenotype acute leukemia, and acute undifferentiated leukemia. ${ }^{[1,9]}$ In AMLs, xeno-cannibalism has been associated with $\mathrm{t}(8 ; 16)(\mathrm{p} 11 ; \mathrm{p} 13), \mathrm{t}(16 ; 21)(\mathrm{p} 11 ; \mathrm{q} 22), \mathrm{t}(10 ; 17)(\mathrm{p} 13 ; \mathrm{p} 12)$, $\operatorname{inv}(8)(\mathrm{p} 11 \mathrm{q} 13), \quad \mathrm{t}(16 ; 21)(\mathrm{p} 11 ; \mathrm{q} 22), \quad \mathrm{t}(3 ; 8 ; 7)(\mathrm{q} 27 ; \mathrm{p} 11 ; \mathrm{q} 12)$, $\operatorname{del}(20)(\mathrm{q} 11)$, and $\mathrm{t}(8 ; 21)(\mathrm{q} 22 ; \mathrm{q} 22) \cdot{ }^{[1]}$

Although conventional lymphocytes and their precursors are inherently nonphagocytic, cannibalism by leukemic lymphoblasts has been reported in nine patients till date. ${ }^{[1-6]}$ The first documentation of xeno-cannibalism in lymphoblasts was by Foadi et al. in 1978, where both erythrophagocytosis and thrombophagocytosis were observed in four relapsed
ALL patients, but the lineage commitment of these lymphoblasts was not disclosed. ${ }^{[4]}$ In 1984, Colon-Otero et al. reported the first case of erythrophagocytosis by lymphoblasts in a newly diagnosed B-ALL patient. ${ }^{[2]}$ Till date, to our knowledge, cannibalism has been documented in only five treatment-naïve B-ALL patients (one adult and four pediatric) and ours is the sixth case in this genre. ${ }^{[1-3,5]}$ The clinical and laboratory characteristics of these six patients are compiled in Table 1.

Interestingly, all the five pediatric B-ALL patients with cannibalistic lymphoblast were positive for ETV6-RUNX1 fusion (100\%). A lone adult B-ALL patient diagnosed with cannibalistic B-lymphoblasts had del (20)(q11), a cytogenetic aberrancy that has also been reported in AML and MDS patients with cannibalism. ${ }^{[10]}$ None of these patients had concurrent hemophagocytic histiocytosis in the bone marrow. Interestingly, $67 \%$ of these patients had near-normal platelet counts, and lymphoblasts of all these patients $(100 \%)$ showed intracytoplasmic vacuolations. These intracytoplasmic vacuolations were also observed in the relapsed ALL patients documented by Foadi et al. ${ }^{[4]}$ Comprehensive FCI data available in four patients revealed the aberrant expression of myeloid lineage antigens (CD13 and/or CD33) in all (100\%).

As lymphocytes and their precursors are inherently nonphagocytic, acquisition of phagocytic phenotype in leukemic lymphoid blasts is unexpected. In relapsed lymphoblastic leukemia patients presenting with cannibalism, Foadi et al. have hypothesized that prolonged exposure to chemotherapy might have triggered a new clone of leukemic lymphoblasts bestowed with phagocytic capability. However, chemotherapy exposure is less likely to be a risk factor as $60 \%$ (six of ten cases described) of B-ALL patients with cannibalistic lymphoblasts were treatment naïve.

Colon-Otero et al. have proposed that acquisition of phagocytic property in treatment-naïve lymphoblasts might be due to tumor cell dedifferentiation causing aberrant expression of complement receptors (CR1 and CR3), receptors for $\mathrm{Fc}$ region of $\mathrm{IgG}$ and gp150 (receptor for fimbriae) on the blasts. ${ }^{[2]}$ However, prospective evidences demonstrating expression of these above-mentioned receptors in cannibalistic B-lymphoblasts are not available. Hence, the pathogenesis of cannibalism in leukemic B-lymphoblast is still an enigma.

Regarding the prognostic relevance of cannibalistic B-lymphoblasts, an elderly treatment-naïve B-ALL patient with del (20)(q11) and all the four relapsed B-ALL patients presenting with cannibalistic lymphoblasts had dismal outcomes marred with either disease relapse or mortality. ${ }^{[2,4]}$ However, all the newly diagnosed pediatric B-ALL patients, including those diagnosed above 10 years of age, were ETV6-RUNX1 fusion positive and had optimistic survival without disease relapse or mortality. 


\begin{tabular}{|c|c|c|c|c|c|c|}
\hline & Colon-Otero et al..$^{[2]}$ & Meeren et al. ${ }^{[3]}$ & Park et al..$^{[1]}$ & Olaiya et al..$^{[5]}$ & Klein et al..$^{[6]}$ & Current \\
\hline Year & 1984 & 2012 & 2013 & 2018 & 2019 & 2020 \\
\hline Country & The USA & Belgium & Korea & The USA & France & India \\
\hline Age & 87 & 4 & 3 & 14 & 4 & 14 \\
\hline Sex & Male & Female & Male & Female & Male & Male \\
\hline $\mathrm{Hb}$ in $\mathrm{g} / \mathrm{L}$ & 105 & 95 & 81 & 47 & 67 & 49 \\
\hline WBC count $\times 10^{9} / \mathrm{L}$ & 1.5 & 10.4 & 7.9 & NA & 7.6 & 3 \\
\hline Platelets $\times 10^{9} / \mathrm{L}$ & 220 & 126 & 183 & 57 & 85 & 127 \\
\hline BM blast \% & NA & NA & 72 & 90 & 98 & 96 \\
\hline PB blast $\%$ & NA & 17 & 16 & 21 & 54 & 75 \\
\hline Splenomegaly (\%) & No & NA & No & NA & Yes & No \\
\hline Hepatomegaly (\%) & No & NA & No & NA & Yes & Yes \\
\hline Karyotyping & 46,XY, del(20)(q11) & Complex* & $\begin{array}{l}46, X Y, t(12 ; 21) \\
(p 13 ; q 22)\end{array}$ & Near-tetraploid** & $46, x y[20]$ & Not done \\
\hline Extramedullary disease & Absent & Absent & Absent & Absent & Absent & Absent \\
\hline ETV6-RUNX1 fusion & Absent $^{\#}$ & Present & Present & Present & Present & Present \\
\hline Vacuolated blasts & Present & Present & Present & Present & Present & Present \\
\hline Xeno-cannibalism & Present & ND & Present & Present & Present & Present \\
\hline Homotypic-cannibalism & Absent & Present & Present & Absent & Absent & Present \\
\hline Associated HLH & Absent & Absent & Absent & Absent & Absent & Absent \\
\hline FCI aberrancy & ND & ND & $\mathrm{CD} 13+, \mathrm{CD} 33+$ & CD13+, CD33+ & CD33+ & CD13+, CD33+ \\
\hline Outcome & $\begin{array}{l}\text { Relapsed after } \\
8 \text { months }\end{array}$ & $\begin{array}{l}\text { Uneventful till } \\
14 \text { months }\end{array}$ & $\begin{array}{l}\text { Uneventful till } \\
\text { maintenance }\end{array}$ & $\begin{array}{l}\text { Uneventful for } 5 \\
\text { years }\end{array}$ & Not available & $\begin{array}{l}\text { Defaulted but } \\
\text { uneventful till } 8 \text { months }\end{array}$ \\
\hline
\end{tabular}

*46 47,XX, add(8)(q23), del(12)(p11.2), add(19)(q13.3), $+\operatorname{add}(21)(\mathrm{p} 11.2), * * 87<4 \mathrm{n}>, \mathrm{XX},-\mathrm{X},-\mathrm{X}, \operatorname{add}(1)(\mathrm{p} 36.1) \times 2,-7,-8, \operatorname{add}(12)(\mathrm{p} 11.2)$, $\operatorname{add}(12)(\mathrm{p} 12),-14,-15, \operatorname{add}(15)(\mathrm{q} 15), \operatorname{der}(20) \mathrm{t}(5 ; 20)(\mathrm{q} 12 ; \mathrm{p} 11.2),+\operatorname{add}(22)(\mathrm{p} 11.2)$, add(22)(q12), "Not evaluated by reverse-transcriptasepolymerase chain reaction or by fluorescent in situ hybridization. NA - Not available; ND - Not declared; HLH - Hemophagocytic lymphohistiocytosis; FCI - Flow cytometric immunophenotyping; Hb - Hemoglobin; WBC - White blood cell, BM - Bone marrow, PB - Peripheral blood

\section{Conclusion}

Due to the limited number of cases documented in literature, it is still premature to arrive at any concrete conclusions regarding the prognostic and clinical relevance of cannibalistic B-lymphoblasts. However, our manuscript highlights that all reported B-ALL patients showing cannibalistic lymphoblasts had intracytoplasmic vacuolations $(100 \%)$, and all such treatment-naïve pediatric patients were ETV6-RUNXI fusion positive (100\%) with aberrant expression of myeloid lineage antigens.

\section{Declaration of patient consent}

The authors certify that they have obtained all appropriate patient consent forms. In the form, the legal guardian has given his consent for images and other clinical information to be reported in the journal. The guardian understands that names and initials will not be published and due efforts will be made to conceal identity, but anonymity cannot be guaranteed.

\section{Financial support and sponsorship}

Nil.

\section{Conflicts of interest}

There are no conflicts of interest.

\section{References}

1. Park JE, Park IJ, Lim YA, Lee WG, Cho SR. Hemophagocytosis by leukemic blasts in B lymphoblastic leukemia with $\mathrm{t}(12 ; 21)$ (p13;q22); TEL-AML1 (ETV6-RUNX1): A case report. Ann Clin Lab Sci 2013;43:186-9.

2. Colon-Otero G, Li CY, Dewald GW, White WL. Erythrophagocytic acute lymphocytic leukemia with B-cell markers and with a 20q- chromosome abnormality. Mayo Clin Proc 1984;59:678-82.

3. Meeren S, Werff Ten Bosch J, Jochmans K. Phagocytic blasts in B-lineage acute lymphoblastic leukaemia. $\mathrm{Br} \mathrm{J}$ Haematol 2013;160:122.

4. Foadi MD, Slater AM, Pegrum GD. Erythrophagocytosis by acute lymphoblastic leukaemic cells. Scand J Haematol 1978;20:85-8.

5. Olaiya OO, Li W. Frequent erythrophagocytosis by leukemic blasts in B-cell acute lymphoblastic leukemia. Blood 2018;131:2178.

6. Klein E, Derrieux C, Dulucq S. Hemophagocytosis by blasts in acute lymphoblastic leukemia. Blood Res 2019;54:2.

7. Kale A. Cellular cannibalism. J Oral Maxillofac Pathol 2015;19:7-9.

8. Sharma N, Dey P. Cell cannibalism and cancer. Diagn Cytopathol 2011;39:229-33.

9. Gupta A, Modi CJ, Gujral S. Hemophagocytosis by leukemic cells in biphenotypic acute leukaemia: A rare case. Indian J Pathol Microbiol 2010;53:370-1.

10. Mori H, Tawara M, Yoshida Y, Kuriyama K, Sugahara K, Kamihira S, et al. Minimally differentiated acute myeloid leukemia (AML-M0) with extensive erythrophagocytosis and del (20)(q11) chromosome abnormality. Leuk Res 2000;24:87-90. 